Mika Kato, Stefan Mittnik, Daniel Samaan and Willi Semmler

\title{
Employment and Output Effects of Climate Policies
}

Technical Report Number 149, 2013

Department of Statistics

University of Munich

http://www.stat.uni-muenchen.de 


\title{
Employment and Output Effects of Climate Policies*
}

\author{
Mika Kato $^{\dagger}$ Stefan Mittnik ${ }^{\ddagger}$ Daniel Samaan ${ }^{\S}$ Willi Semmler $₫$
}

August 2012, this version: November 2013

\begin{abstract}
Recently academic work has been put forward that argues for a great urgency to implement effective climate policies to stop global warming. Concrete policy proposals for reducing CO2 emissions have been developed by the IPCC. One of the major instruments proposed is a carbon tax. A main obstacle for its implementation, however, are concerns about the short-term effects on employment and output. In order to mitigate possible negative effects of enviromental taxes on output and employment, several European countries have introduced so-called environmental tax reforms (ETR) which are designed in a budget neutral manner: Revenues from the tax can be used to reduce existing distortionary taxes or to subsidize less polluting activities. We apply this idea to a carbon tax scheme by performing a vector autoregression (VAR) with output and employment data of nine industrialized countries. We impose a simultaneous policy shock on the economy whereby a carbon tax is levied on high-carbon intensive industries and the resulting tax revenue is redistributed to low-carbon intensive industries. Impulse response analysis shows that such a policy allows for net gains in terms of output and employment.
\end{abstract}

${ }^{*}$ Earlier versions of this paper have been presented at the International Institute for Labour Studies at ILO, Geneva, at the 36th Annual Meetings of the Eastern Economic Association, Philadelpia, February 2010, "The Economics of Climate Change" conference at the the New School hosted by SCEPA, New York, April 2010 and at Manchester University in July 2010. The paper was also discussed at the "Meeting of the Task Force on Global Warming" organized by Joseph Stiglitz in July 2010. We thank all participants for the comments provided.

${ }^{\dagger}$ Department of Economics, Howard University, Washington D.C.

${ }^{\ddagger}$ Center for Quantitative Risk Analysis, Department of Statistics, Ludwig-Maximilians-Universität München, Munich.

$\S$ International Institute for Labour Studies, ILO, Geneva.

『Department of Economics, New School for Social Research, New York. 


\section{Introduction}

It is now well recognized that global warming results from economic activities that create $\mathrm{CO}_{2}$ emissions. Academic work has thus been put forward that argues for a great urgency to implement effective climate policies to control global warming. Concrete policy proposals for reducing $\mathrm{CO}_{2}$ emissions have been developed by the Intergovernmental Panel on Climate Change (see for example IPCC (2006) and IPCC (2007)). Given this recently published scientific evidence on global warming and its damages, the importance of climate change mitigation policies has been sufficiently demonstrated.

On the other hand, it has been recognized by the IPCC and other studies that climate change is not only an environmental problem but that over the long run global warming is likely to have drastic effects on economic activity. Economic growth and climate change are increasingly seen as interdependent issues (see Uzawa (2003), Stern (2007), Greiner and Semmler (2008), Nordhaus (2008) and Weitzmann (2008)). Different approaches exist to analyze these interdependencies, to measure the cost and to derive appropriate policy recommendations. Based on the assumptions used and the respective climate or economic model employed the degree of urgency for action differs. Hansen (2008) or Greiner, Gruene, and Semmler (2010), for example, argue that due to the possibility of self enforcing feedback effects, a much faster and stronger policy response is required than most other models suggest. Greiner, Gruene, and Semmler (2010) also provide a brief review about differing modeling approaches and their conclusions. Despite these differences in the analysis of the problem, there is wide agreement among scholars that some policy measures need to be implemented in order to stop or to slow down the anthropogenic climate change.

Correspondingly, a recent report by the IPCC (4th Assessment Report) has urgently suggested a broad range of mitigation policy measures, such as integrating climate policies, broader development policies, regulations and standards, voluntary agreements, information instruments and financial incentives to control and reduce Greenhouse Gas (GHG) emissions. ${ }^{1}$ It also emphasizes the role of technology policies to achieve lower $\mathrm{CO}_{2}$ stabilization levels, a greater need for more efficient R\&D efforts, and higher investment in new technologies during the next few decades (for achieving stabilization and reducing costs). Further recommendations include government initiatives for funding or subsidizing alternative energy sources (solar energy, ocean power, windmills, biomass, and nuclear fusion). Overall, the IPCC stresses the fact that the effectiveness of such policies ultimately depends on national circumstances, their design, interaction, stringency and implementation.

Yet, the major instruments that the IPCC and numerous well-respected economists propose are two specific tools to reduce GHG in order to fulfill the agreements of the Kyoto protocol. These two tools are decentralized market trading of emission rights and carbon taxation - in the public discussion often called "cap-and-trade" and "carbon tax" (see Uzawa (2003), Nordhaus (2008), Mankiw (2007) and also the IPCC). A tax on carbon as a means to reduce $\mathrm{CO}_{2}$ emissions has been suggested by economists for quite some time (see Pearce (1991)). Both measures have a long standing history in economic theory originating in the works of Pigou (1920) and Dales (1968). Independently of how these measures may look in detail, it is obvious that such policies will have

\footnotetext{
${ }^{1}$ We limit the discussion to the reduction of $\mathrm{CO}_{2}$ emissions since $\mathrm{CO}_{2}$ emissions account by far for the largest portion of GHG and most other GHG are accounted for in terms of $\mathrm{CO}_{2}$ equivalents in available statistics.
} 
an impact on economic activity and employment.

This paper analyzes the effects of a carbon tax on output and employment. A carbon tax incentivitizes the avoidance of carbon intensive production schemes and penalizes the consumption of carbon intensive goods and services. Over the long term a carbon tax thus leads to some form of structural change in the economy. This structural change may cause costs in terms of unemployment and in terms of reduced consumption possibilities today or in the future. In neoclassical growth models with immediate clearing markets, the adjustment costs within an economy in terms of employment fluctuations are assumed to be zero. However, it seems reasonable to expect that different sectors in an economy would react differently to a carbon tax in terms of output and employment. We can expect that some sectors in the economy will increase in size, or that even new sectors emerge, while other sectors decrease or even disappear. The net effect on emplyoment may be positive or negative.

Structural change is usually understood as the massive reallocation of labor from the primary sector (agriculture) into the secondary (manufacturing) and tertiary (services) sectors. Many economists, for example Fisher (1935), Clark (1940), Kuznets (1957), Kaldor (1957) or Cherney (1960) have well documented such a transition and have developed models that allow for the study of growth and structural change simultaneously. In Pasinetti (1981), for example, structural change occurs through a change in final demand driven by the income elasticity of demand (Engel curves).

These ideas principally also apply for the structural change required to cope with global climate change. However, instead of focussing on types of goods or sectors (agriculture, manufacturing, services) to describe the structure of an economy, the transition towards a sustainable ("low carbon") economy can be analyzed based on the criterion of carbon-intensity of goods, sectors and activities. Whatever climate policies will be implemented by policy makers in the future (regulations, carbon tax, emission trading systems or others), their economic effect will be to strengthen the relative position of low-carbon industries in the economy, i.e. industries emit a loower amounts of $\mathrm{CO}_{2}$ during the production process. In addition, incentives are created for industries to develop techniques and products which allow for a low-carbon production of output. Kato, Semmler, and Samaan (2010) have devloped a three-sector growth model in which the economoy experiences structural change on a balanced growth path. The high-carbon intensive sector decreases in relative size while the relative size of the low-carbon sector increases. The main mechanism of the model is sketched in the appendix.

Thus, similar to the more traditional idea of structural change, a transition towards a lowcarbon economy could be characterized by focussing on the structure of output and employment in the economy. In particular, a re-allocation of labor from the more traditional sectors ("high carbon intensive sector") to the "low carbon intensive" would mean that future jobs are created in the low carbon intensive sector while jobs would disappear in the high carbon intensive sector. Theoretically, structural economic change can occur by itself (and often does), i.e. without government intervention. Changing relative prices, changing consumer preferences,new technological developments or other factors can be the cause for a structural change. For example, neither was government intervention needed to induce a structural change from an industrial economy to a more service oriented economy nor was this a goal. Fuchs (1968) identifies three factors as driving forces for structural change in the traditional sense: 
First, the income elasticity of the demand for services is greater than one. Second, as income rises it becomes more efficient to contract out services that were once produced in the household or firm. Third, productivity growth is slower in the service sector. For a more recent discussion of structural change in a theoretical growth model, see also Kongsamut et al. (2001)).

In the case of a structural change towards a low-carbon economy, the situation is somewhat different since some form of government activity is required. From an economic point of view, pollution such as $\mathrm{CO}_{2}$ emissions constitute a negative externality that needs to be internalized. Therefore, the government has to play an active role in this process, for example through implementation of a Pigou Tax in the form of a carbon tax.

It has been quite controversial what the employment effects of such a policy would be. Pearce (1991) already pointed out that a carbon tax could yield a double dividend, if it replaces a distorting tax like a labor tax. His conclusion is in line with the hypothesis that Porter (1990) makes in a broader context, namely that the economy would gain competitiveness through implemented environmental policies. For Porter and van der Linde (1993), it is accelerated technical change, and higher innovativeness of enterprises that leads to increased competitiveness in the long run. Others have challenged this view on theroetical grounds (see for example Palmer, Oates, and Portney (1995)). Overall, the question about employment and competitive effects remains unresolved and subject to debate. Anderson and Ekins (2009) and Ekins and Speck (2011) provide recent evidence on economic effects of environmental tax reforms (ETRs) in European countries.

In this contribution, we focus on the short-term employment dynamics that could be triggered by a carbon tax, ignoring long-term technical change. In particular, we are interested in the effects of a budget neutral carbon tax scheme in which the collected tax revenue is re-injected into the economy, similar to ETR schemes that have been implemented in several Euopean countries. We argue that even without considering technological change, positive or negative employment effects can occur in a two sector model, depending on the growth and employment dynamics in the sectors. We analyze a tax scheme in which the carbon tax is only imposed on the the high-carbon intensive sector of the economy and in which revenue is shifted towards the low-carbon sector. We assume that, in the short run, tax increases lead to a negative output growth shock while subsidies lead to a boost in output growth. The rationale behind this assumption is that technical change and innovation take time. In the short run a tax has a depressing effect on output while a tax decrease or subsidy encourages economic activity.

A review of the debate on the double dividend, a discussion of different versions of it and evidence for and against it, is provided in the following section.

\section{The Double Dividend in the Literature}

In case of a carbon tax, or more generally, environmental taxes, the academic literature discusses possible positive employment effects the in the context of the so called double dividend hypothesis. Different notions of a double dividend exist and following Goulder (1995b) we review different concepts of the double dividend on theoretical as well as on empirical grounds. 
Economists have even been wondering if correcting for environmental externalities can at the same time generate a positive effect ("double dividend hypothesis"). At least three versions of the double dividend hypothesis exist (see Goulder (1995b)). The first dividend would be an increase of environmental quality. Emission of $\mathrm{CO}_{2}$ constituted an externality if it leads to damages in the environment which in economic terms means that these damages cause a decrease in production, decreased profits or some other form of welfare losses. The market solution therefore provides an inefficient allocation. Correcting this externality with a Pigou tax is welfare improving and results in efficiency gains.

Dealing with this kind of externality $\left(\mathrm{CO}_{2}\right.$ emission) is a very complex problem: First, polluters have been polluting in the present and in the past while most of the damages will occur in the future. Second, the aggrieved parties are to a large extent unborn future generations. Third, since the damages occur mainly in the future and because the climate system is very complex and not fully understood, the magnitude of future damages is highly uncertain. In other words, the cost of the externality is difficult to quantify. Finally, the greenhouse effect is a global problem and polluters and aggrieved parties therefore need not to reside in the same country or even the same region of the world.

The previous points make an internalization of such external effect extremely difficult from a political perspective. However, considering the world population as a whole and looking at world GDP, the current allocation, i.e. mostly unregulated $\mathrm{CO}_{2}$ emissions is inefficient and it is generally recognized that removing the externality leads to a Pareto improvement. Thus, it is possible to move to a world GDP growth path on which no one is worse off but some people may be better off. Internalizing the external effect is the first dividend. We refer to this first dividend as environmental benefits even though we emphasize that these benefits can very well be translated into tangible economic terms.

The problem with this first dividend, which justifies by itself the implementation of a tax or other correcting instrument, is that the magnitude of the benefits are uncertain and may lie far in the future (see Goulder (1995b)). The implementation of the tax does, however, cause gross costs in the form of behavioural changes compared to the status quo which are very certain, quantifiable and occur in the present. In other words, while the net cost of a properly designed $\mathrm{CO}_{2}$ tax has to be negative, i.e. produce global welfare gains, there is a gross cost to the tax; which is imposed on those who currently over-emit $\mathrm{CO}_{2}$. This gross cost is usually expressed in terms of reductions in current GDP growth for some countries including possible employment losses. The implementation of such an instrument (carbon tax) constitutes therefore a rather unattractive situation for policy makers.

Out of this dilemma, policy makers have developed a preference for the double dividend hypothesis which claims that the gross cost of a carbon tax (environmental tax) be zero or even negative. Under these circumstances, the implementation of the tax would be either costless or beneficial no matter what the magnitude of the environmental benefits is (as long as they are still positive). If costs are zero (or negative), this guarantees positive net benefits. On the other hand, if one cannot be assured that the costs are zero, then before one can recommend an environmental tax swap on efficiency grounds one has to be involved in the messy business of comparing (uncertain) environmental benefits with abatement costs (Goulder (1995b)). The main mechanism that can reduce gross costs of a carbon tax is revenue recycling. If the raised revenue is used to reduce distortionary 
taxes the total cost of the tax can be reduced or even become zero or negative. It is important to keep in mind that we are talking about the gross cost, i.e. excluding the environmental benefits which, if included, would always lead to a net negative cost or welfare improvement.

Goulder (1995b) distinguishes three versions of the double dividend hypothesis which depend on the size of the cost reduction of the implemented carbon tax (environmental tax). The weak form claims that one achieves cost savings relative to the case where the tax revenues are returned to taxpayers in lump-sum fashion if the tax revenues are instead used to reduce marginal tax rates of a distortionary tax. The intermediate form claims that it is possible to find a distortionary tax such that the revenue-neutral substitution of the carbon tax (environmental tax) for this tax involves a zero or negative gross cost. The strong form claims that the revenue-neutral substitution for typical or representative distortionary taxes involves a zero or negative cost.

The terms "cost reduction" or "zero or negative cost" have to be understood here in a general way for a number of welfare gains. Often these welfare gains are specified in concrete economic terms such as reduced unemployment or increased profits (see for example Bovenberg and van der Ploeg (2002), Carraro, Galeotti, and Gallo (1996) or Nielsen, Pedersen, and Sorensen (1995)). Thus, in our context of employment effects, the second dividend concerns the question of reduced unemployment caused by a reduction of distortionary taxes which is financed through a carbon tax (environmental tax). Typical candidates for distortionary taxes to be reduced are all kinds of labor costs like wage taxes or social security contributions.

On theoretical grounds, the claims of the weak double dividend are widely accepted and are considered relatively uncontroversial (see Goulder (1995b)). Bovenberg and de Mooij (1994) develop a general equilibrium model to study the strong version of the double dividend claim in the labor market context. The only tax in their model is a labor income tax. They find that the strong claim is substantiated if and only if the uncompensated wage elasticity of labor supply is negative. Empirical studies tend to find positive values for the uncompensated elasticity so that the Bovenberg-de-Mooij model suggests a rejection of the double dividend hypothesis in its strong form.

Both conclusions, the general acceptance of the weak form and the rejection of the strong form in the Bovenberg-de-Mooij model, depend crucially on the assumptions about the tax system in place when the carbon tax (environmental tax) is implemented as well as the mechanisms in place on the labor market. Under idealized market conditions with perfect competition, a commodity tax can and a tax on wage can be designed equivalently in terms of costs (see Kaplow (2008)). In other words, distortions in the labor and commodity markets are interrelated. An environmental tax on the commodity markets can therefore have distorting effects on the labor market as well thereby reducing the potential of a strong double dividend. As Goulder (1995b) points out, a main insight of the Bovenberg-de-Mooij analysis is that partial equilibrium analyses of the gross costs of environmental taxes can be highly misleading and that the question of a possible double dividend in the real world is very complex: In Bovenberg and de Mooij (1994), the authors use a dynamic model and then find that double dividend may be possible if ETRs lead to lower regulatory pressure on companies. Nielsen, Pedersen, and Sorensen (1995) analyse the double dividend hypothesis with a model that allows for involantary unemployment and show that unemployment can be reduced through the implementation of a pollution tax.

Despite the complexity of the mechanisms that may or may not lead to a double dividend, 
one can draw some general conclusions on the theoretical conditions under which a strong double dividend is likely to occur. The gross costs of revenue-neutral environmental tax will be lower to the extent that (Goulder (1995b)):

1. in the initial tax system, the difference in the marginal efficiency costs (marginal excess burdens) is large,

2. the burden of the environmental tax falls primarily on the factor with relatively low marginal efficiency cost,

3. the base of the environmental tax is relatively broad, so that the distortions it generates in intermediate good and consumer good markets are small and,

4. revenues from the tax are devoted to reducing tax rates on the factor with relatively high marginal efficiency cost.

Other aspects to be taken into account in the theoretical analysis concern the question whether capital is considered, whether involuntary unemployment exists, whether markets clear, or if the environment is treated as a capital good. Another important dimension is the question whether one deals with an open or a closed economy.

Several reviews about the employment effects of environmental policies have been prepared by the OECD over the last decades (OECD, 1978), (OECD, 1997), (OECD, 2004) and Chateau, SaintMartin, and Manfredi (2011) who employ the OECD ENV-linkages model to simulate the effects of climate change policies on employment. In its 2004 report, the OECD also reviews the evidence of employment effects related to climate policies of OECD countries and draws some conclusions on the double dividend hypothesis. Generally, the extent to which a double dividend may be earned through environmental taxes depends largely on the already existing tax system of an economy. The interaction of environmentally related taxes with other taxes (for example replacement or reduction of taxes on labor through energy taxes) may than in total have a positive effect on employment. The OECD also points out that the current state of the labor market has to be considered before a meaningful evaluation of the double dividend hypothesis can be undertaken.

Some studies on the employment effects of environmental or climate policies disregard economic feedback effects and mainly just determine if a number of jobs have directly been created in a particular (environmentally related) sector. More comprehensive studies employ some kind of theoretical model. Different models make different assumptions about the labor markets and the economic mechanisms at work, for example, just with respect to the processes at the labor market, one could employ a wage bargaining model, an efficiency wage model or a job-matching model. In Chateau, Saint-Martin, and Manfredi (2011), OECD uses an computable general equilibrium model to estimate employment effects and finds evidence for the double dividend in its strong version for several OECD countries.

OECD (2004) roughly groups the economic models into a) econometric models that are usually demand driven and allow for disequilibrium markets b) general equilibrium models which are based on simultaneous equilibria on all involved markets and c) partial equilibrium models. Most models assume exogenous technical change and exogenous and fixed preferences. Due to the variety of 
assumptions that may still be be altered, different results arise. However, the OECD can identify some general tendencies regarding the potential occurrence of a double dividend (OECD (2004)):

" A strong double dividend cannot occur if the existing tax structure is revenue-optimal. If, as is likely in practice, the existing tax structure is not revenue-optimal, a strong double dividend will occur if the environmental tax reform moves the tax structure in the direction of revenueoptimality. In a situation with involuntary unemployment, employment will only increase if the use of environmental taxes to partially replace existing taxes results in an increased demand for labor. If the labor market is in equilibrium, additional employment could only be caused by increasing labor supply."

On a general level, no necessary or sufficient conditions can be found for when an increase in environmentally related taxes combined with a reduction in e.g. payroll taxes will increase employment - in addition to the first dividend stemming from the reduced externality and the improvement of the quality of life. Based on the study by Heady, Markandya, Blyth, Collingwood, and Taylor (2000), OECD (2004) identifies the following factors that make the occurrence of a double dividend more likely. When there is involuntary unemployment, the prospects of increased employment are higher if:

1. the environmental tax can be passed on to factors that are inelastically supplied and relatively under-taxed.

2. non-working households are large enough in numbers, and are significant as consumers of goods produced with the environmentally intensive inputs that are taxed.

3. through international market power, the environmental tax can raise the price of goods produced with a relatively intensive use of the taxed environmental input.

4. capital is relatively immobile internationally. In this case it can absorb some of the environmental tax and less of the tax burden falls on factors such as labor.

5. the elasticity of substitution between the environmental input and labor is greater than the elasticity of substitution between energy and capital.

6. the real wage rises little when unemployment falls, so that the reduction in the taxes on labor are not offset by wage rises.

When there is only voluntary unemployment, conclusions (1) to (4) still hold, but conclusions (5) and (6) are replaced by: The environmental tax is levied on goods that are more complementary to leisure in consumption than the goods whose taxes are reduced.

A very broad spectrum of econometric based literature on environmental policies and their employment effects exists. We concentrate here on major studies that discuss environmental policies that are or can be considered climate policies.

Several empirical studies have been conducted to analyze the double dividend hypothesis for the U.S. economy. Shackleton, Shelby, Cristofaro, Brinner, Yanchar, Goulder, Jorgenson, Wilcoxen, Shackleton, Shelby, and Cristofaro (1992) make use of the DRI and LINK econometric macroeconomic models for the U.S. as well as of the Goulder and Jorgenson-Wilcoxen intertemporal general 
equilibrium model to answer this question. In all three modeling frameworks, they introduce a phased-in carbon tax accompanied by a cut in the personal income tax. In the framework of the Jorgenson-Wilcoxen model the revenue is recycled through a cut in the labor tax instead of a personal income tax reduction. In terms of welfare changes, the authors look only at the gross costs of the tax, i.e; exclude the welfare gains that we have previously labeled environmental benefits. In the DRI and the LINK model, Shackleton, Shelby, Cristofaro, Brinner, Yanchar, Goulder, Jorgenson, Wilcoxen, Shackleton, Shelby, and Cristofaro (1992) find positive gross costs of the tax, i.e. welfare losses. These results do therefore not support the strong dividend claim. However, in the Jorgensen-Wilcoxen model, they find negative gross costs of the tax if the revenue is used to reduce labor taxes, hence supporting the strong dividend claim.

The reasons for the difference in these results are not entirely clear. Goulder (1995b) suspects that differences in the considerably higher marginal excess burden of capital taxation and the assumption of perfect capital mobility in the Jorgenson-Wilcoxen model are the causes for the different results.

The studies conducted by Goulder (1995a), Goulder (1994) and Shah and Larsen (1992) introduce a constant carbon tax or fossil fuel tax accompanied by reductions in the personal income tax rate. All three studies find positive gross costs of the implemented tax casting further doubt on the strong double dividend hypothesis in its strong form. While these simulation results for the U.S. tend to not support the strong dividend claim there is no agreement on this issue, in particular because the sources of differences in the models are not entirely understood. Simulation results based on data of European economies tend to be a little bit more optimistic about the strong double dividend.

Significant research on climate change has been done by the MIT Joint Program on the Science and Policy of Global Change. The Program integrates multidisciplinary expertise from the Center for Energy and Environmental Policy Research and the Center for Global Change Science and collaborates with other major research groups within and outside MIT. ${ }^{2}$ At the heart of the Joint Program's work lies the MIT Integrated Global System Model (IGSM). This comprehensive tool analyzes interactions among humans and the climate system. The Emissions Prediction and Policy Analysis (EPPA) model is a component of the IGSM (see Babiker, Reilly, Mayer, Eckaus, Wing, and Hyman, 2001) which is also designed to evaluate the economic impacts of policies designed to limit GHG emissions. EPPA belongs to a class of economic simulation models known as computable general equilibrium (CGE) models. Babiker and Eckaus (2007) use the EPPA model to theoretically study the unemployment effects of restrictions on greenhouse gas emissions. A variety of research papers focussing on different economic aspects of the climate change have been produced by the MIT Joint Program ${ }^{3}$.

Babiker and Eckaus (2007) allow for labor market rigidities, for example limited mobility of labor among sectors, and thus include scenarios in which involuntary unemployment occurs. The authors simulate three different scenarios for the following labor market environments: (1) mobile labor and flexible wages, (2) sector specific labor, but flexible wages (3) mobile labor, but rigid wages, (4) sector specific labor and rigid wages. The three climate policy scenarios are: (1) no greenhouse gas policy restrictions (reference solution), (2) Kyoto-like emissions restrictions imposed, without

\footnotetext{
${ }^{2}$ (see http://globalchange.mit.edu/index.html)

${ }^{3}$ (see http://globalchange.mit.edu/pubs/reports.php)
} 
any offsetting policies; (3) Kyoto emissions restrictions, but with labor subsidies to offset the unemployment and economically depressing effects of those restrictions. These cases are similar to the first and second case in our paper (carbon tax and carbon tax with wage subsidies).

Babiker and Eckaus (2007) are hesitant to give exact measures of the effects due to the limits of data and the EPPA model. However, they find similar but not identical empirical results as we do. Their analysis indicates that "there would be a real, direct depressing effect from the imposition of emissions restrictions." The employment effects they anticipate are expected to be only small but negative. The negative effects are mainly caused by a reduction in GDP growth under the implemented climate policies. Thus, in their modeling framework they cannot find support for the double dividend hypothesis. They recommend that other policy measures, for example wage subsidies, be implemented to mitigate negative employment effects of climate policies.

Several EU countries have introduced environmental tax reforms in the past years (see also Ekins and Speck (2011)). Most notably, Germany implemented its so called "ecological tax reform" in 1998, through which an energy tax was introduced and the tax revenue was used to subsidies wage cost. The reform gave reason to conduct several studies on the employment effects of the implemented policy measures. The most comprehensive studies were carried out by Bach, Bork, Kohlhaas, Lutz, Meyer, Praetorius, and Welsch (2001) and Frohn, Chen, Hillebrand, Lemke, Lutz, Meyer, and Pullen (2003). The first study was conducted by the German Institute for Economic Research (DIW) on behalf of the German Federal Ministry of Finance ("Bundesministerium für Finanzen"). Both studies employ simulation models (PANTA RHEI, model system of RWI). The PANTA RHEI model is an econometric model for the German economy. It is a detailed multisectoral model covering 58 industrial branches. In PANTA RHEI, all parameters are estimated by econometric methods using time series of the input-output tables of the German economy. The model has a disaggregated energy and air pollution module. It is built for medium-term forecasts up to 2020. The methodology of PANTA RHEI including empirical results is also discussed in detail by Meyer, Bockermann, Ewerhard, and Lutz (1999) and Meyer (2005). Lutz and Meyer (2008) provide an overview of empirical studies about the effects of the German tax reform that have been conducted over the last years.

Strictly speaking, the German ecological tax reform was not exclusively targeted at achieving climate goals but was thought to serving environmental and energy efficiency goals in general. Consequently, the cited studies analyze a broad variety of economic effects, not only employment. Nevertheless, we can gain some valuable insights on the employment effects of the policy measures, in particular since the tax reform was heavily promoted under the double dividend hypothesis. Germany's ecological tax reform basically boils down to the introduction of energy taxes and an annualy increase of the already existing petroleum tax. The tax revenue has been used to subsidy social security contributions which are levied on labor thereby reducing the effective wage cost. However, large exceptions from the energy tax exist for energy intensive industries and air traffic.

The study by Bach et al. (2001) concludes that the eco tax will reduce Germany's growth only slightly (-0.1 percent) but will have a positive effect on employment and reduce $\mathrm{CO}_{2}$ emissions. However, the latter two effects were also rather small and by no means sufficient to solve either the problem of climate change nor the problem of high unemployment in Germany at that time. Due to these relative small effects, some economists have titled the German reform as an "eco-political fig leaf"' (see Boehringer and Schwager (2003)). 
The simulation of different scenarios in Frohn, Chen, Hillebrand, Lemke, Lutz, Meyer, and Pullen (2003) confirm the results of Bach et al. (2001). All scenarios resulted in slightly positive employment effects and a small reduction of emissions. While the employment increase did not react very strongly to an increase in the tax rates and the abolishment of the eco tax exceptions, $\mathrm{CO}_{2}$ emissions fell stronger in scenarios with higher tax rates an no exceptions from the eco tax. The highest reduction of $\mathrm{CO}_{2}$ emissions was achieved in a scenario with a hypothetical $\mathrm{CO}_{2}$ tax (as opposed to an energy tax). However in this scenario, the still positive employment effect was the weakest and the decelerating effect on macroeconomic activity was the strongest. A switch from the current energy taxation to a $\mathrm{CO}_{2}$ tax is endorsed by most authors. Besides different findings and criticism about the size of the "double dividend" in the case of the German experiment, we can at least conclude that no cumulative negative effects on employment were found.

The Cambridge Econometric E3ME model uses a top-down, macro-economic approach to study the competitiveness effects of a carbon tax at the European level (see Barker, Junankar, Pollitt, and Summerton (2009)). The model focusses competitiveness effects and analyzes short- and long-term effects of price and wage rate changes in the six EU countries that formally implemented ETRs (Denmark, Germany, Netherlands, Finland, Sweden and United Kingdom). Under the assumption of a carbon tax leading to an increase in energy prices, the model illustrates that such a policy would lead to a reduction in the demand for energy and ultimately, to a reduction in carbon emissions. The largest emission reductions occur in countries with the highest tax rate. Moreover, all six countries witness an increase in GDP and national employment, despite some negative short-term transition effects. In some countries, employment even increases by as much as 0.5 per cent.

Departuring from the aforementioned literature on structural change, we propose in the following an econometric model with which we analyse the double dividend hypothesis in its strong form. We suggest a multivariate time series approach utilizing data on employment, output and $\mathrm{CO}_{2}$ emissions of nine industrialized countries.

\section{Data Description}

In our model of structural change, we employ a German data set in order to identify high and low carbon intensive industries. Based on the German industry classification, we use employment and output data from the EU Klems database (http://www.euklems.net/index.html) to estimate in the form of a vector autoregression (VAR) a linear dynamic model of employment in high- and low-carbon industries.

The EU KLEMS database is the outcome of the EU KLEMS project which aims to create a database on measures of economic growth, productivity, employment creation, capital formation and technological change at the industry level for all European Union member states from 1970 onwards and provides a systematic collection of industry specific data. A detailed description of the contents and the construction of the EU KLEMS database can be found in O'Mahony and Timmer (2009). For the most part, data are comparable among countries. Mainly European countries are covered by the database but several other non European economies like the U.S., Japan or South Korea are also included. 
Unfortunately, no data on environmental impacts of industries are included in EU KLEMS and these data (in particular data on $\mathrm{CO}_{2}$ emissions) have to be taken from alternative sources. The level of disaggregation in EU KLEMS is for many countries by and large similar to common input-output tables and are therefore more or less compatible with information from input-output tables. However, no coefficients are provided by EU KLEMS so that computations that involve input-output coefficients have to be made on basis of I/O tables and EU KLEMS together. This is not always possible or requires adjustment of data, in particular if the industries in one database do not match exactly with the industries in the other data base.

We use data from German input-output tables (2005) to exemplarily generate the two sectors, a high carbon-intensive sector (HCIS), and a low carbon intensive sector (LCIS). German inputoutput tables are provided by the Federal Statistical Office ("Statistisches Bundesamt") and are available at a 71 sector level. In addition to traditional input-output tables, the German Federal Statistical Office provides industry specific data on $\mathrm{CO}_{2}$ emission in kilo tons.

With these data, we calculate the $\mathrm{CO}_{2}$-intensity of each industry measured in kilo tons over gross output in million euros (direct $\mathrm{CO}_{2}$ intensity). This ratio describes how many kilo tons of $\mathrm{CO}_{2}$ emissions a specific sector in the economy requires in order to generate one million Euro of gross output. With the help of these key figures, we rank different industries according to their $\mathrm{CO}_{2}$ intensity and classify industries in the two sectors (HCIS and LCIS). Industries whose carbon intensity per unit of output is above (below) the median are classified as belonging to the highcarbon intensity (low-carbon intensity) sector. Note that this grouping has been done on basis of the German $\mathrm{CO}_{2}$ intensity data (2005), i.e. the ranking of industries is identical for all countries analyzed.

The absolute level of $\mathrm{CO}_{2}$ emissions as well as the absolute $\mathrm{CO}_{2}$ intensity in a particular sector may of course differ among countries. This depends on the size of the industry, the technology used, the energy mix and possibly on other factors. However, the relative position of an industry within a country can be expected to be roughly the same, especially among industrialized countries. Thus, energy intensive manufacturing industries like metals, coke, mechanical wood and can be expected to be relative high carbon intensive in any country. Since we have just two sectors (HCIS and LCIS), only changes in $\mathrm{CO}_{2}$ intensities of industries around the median have an effect on the composition of the HCIS and LCIS in a country. Following an input-output modelling approach by Proops, Faber, and Wagenhals (1993), we also calculated total $\mathrm{CO}_{2}$ intensity. This method takes also the carbon intensity of inputs into account and produces therefore more accurate results on $\mathrm{CO}_{2}$ productivity of certain industries. This alternative calculation did, however, not affect the industry composition of the two sectors, HCIS and LCIS.

As a next step, we use the industry time series data from EU KLEMS to determine the past growth of output and employment in the HCIS and the LCIS for nine industrialized countries. The countries examined are Germany, Australia, France, Hungary, Japan, South Korea, Sweden, U.K. and the United States. Table 1 summarizes the obtained sample. 
Table 1: Time Series: Employment and Output of HCIS and LCIS

\begin{tabular}{llcc}
\hline$\#$ & Country & Years & Observations \\
\hline & & & \\
1 & Germany & $1992-2005$ & 14 \\
2 & Australia & $1989-2005$ & 17 \\
3 & France & $1978-2005$ & 28 \\
4 & Hungary & $1992-2005$ & 14 \\
5 & Japan & $1973-2005$ & 33 \\
6 & South Korea & $1970-2005$ & 36 \\
7 & Sweden & $1970-2005$ & 36 \\
8 & United Kingdom & $1970-2005$ & 36 \\
9 & USA & $1970-2005$ & 36 \\
& & & \\
\hline
\end{tabular}

\subsection{Model}

We specify a first-order, four-variable VAR model comprising high-carbon intensity output, denoted by $O U T_{h i, t}$, low-carbon intensity output $\left(O U T_{l o, t}\right)$, high-carbon intensive employment $\left(E M P_{h i, t}\right)$ and low-carbon intensive employment $\left(E M P_{l o, t}\right)$. All variables in the VAR are specified in terms of annual growth rates (i.e., log-differences) and collected in a vector $y_{t}$, defined by

$$
y_{t}=\left[\begin{array}{c}
\text { out }_{h i, t} \\
\text { out }_{l o, t} \\
\text { emp }_{h i, t} \\
\text { emp }_{l o, t}
\end{array}\right]=\left[\begin{array}{c}
\log O U T_{h i, t}-\log O U T_{h i, t-1} \\
\log O U T_{l o, t}-\log O U T_{l o, t-1} \\
\log E M P_{h i, t}-\log E M P_{h i, t-1} \\
\log E M P_{l o, t}-\log E M P_{l o, t-1}
\end{array}\right] \times 100
$$

The first-order VAR is of the form

$$
y_{t}=c+A y_{t-1}+\varepsilon_{t},
$$

with disturbances $\varepsilon_{t}$ satisfying $\mathrm{E}\left(\varepsilon_{t}\right)=0$, and

$$
\operatorname{Cov}\left(\varepsilon_{t}, \varepsilon_{s}\right)= \begin{cases}\Sigma, & t=s, \\ 0, & t \neq s,\end{cases}
$$

and $c$ and $A$ being a constant parameter vector and matrix, respectively, and $\varepsilon_{t}$ denoting the onestep-ahead prediction error. Table 2 shows summary statistics of the data set for the U.S. with which we continue our discussion.

Multivariate least square (MLS) estimation of the parameters yields the following results: 


$$
\hat{c}_{U S A}=\left[\begin{array}{l}
1.25 \\
3.25 \\
0.54 \\
0.58
\end{array}\right], \hat{A}_{U S A}=\left[\begin{array}{cccc}
0.37 & 0.52 & 0.20 & -0.92 \\
0.47 & 0.76 & -0.23 & -0.54 \\
-0.02 & 0.23 & 0.50 & -0.26 \\
-0.06 & 0.51 & 0.27 & -0.33
\end{array}\right], \hat{\Sigma}_{U S A}=\left[\begin{array}{cccc}
5.67 & 2.45 & 1.80 & 2.89 \\
2.45 & 7.40 & 1.74 & 3.57 \\
1.80 & 1.74 & 1.11 & 1.57 \\
2.89 & 3.57 & 1.57 & 2.91
\end{array}\right]
$$

With the eigenvalues of $\hat{A}_{U S A}$ being $0.2164 \pm 0.5489 i, 0.5322$ and 0.3444 , and the moduli being $0.59,0.5322$ and 0.3444 , the estimated system is stable.

For the t-ratios, we obtain:

$$
T_{U S A}=\left[\begin{array}{ccccc}
1.58 & 1.64 & 2.50 & 0.24 & -1.39 \\
3.59 & -1.82 & 3.20 & -0.24 & -0.72 \\
1.55 & -0.24 & 2.53 & 1.36 & -0.90 \\
1.03 & -0.38 & 3.41 & 0.45 & -0.71
\end{array}\right]
$$

We have the choice between d.f $=K T-K^{2} p-K$ and d.f. $=T-K p-1$ for the number of degrees of freedom, whereby $K$ denotes the number of variables and $T$ the sample size. In the case of the United States, we have d.f. $=116$ or d.f. $=29$. For a two-tailed t-test at the $5 \%$ level, we get critical values between 2.048 and 2.365 , indicating that several coefficients are not significant under this criterion.

The coefficients of the variable out $t_{l o, t}$ are all significant at the $5 \%$ level for d.f. $=29$.

Clearly, in view of the the data limitations, higher than first-order VARs cannot be estimated. However, given that we work with annual data, a first-order VAR should be sufficient for a principal approximation of the employment-output dynamics.

We continue the analysis here with the U.S. data. The estimatation results for all other countries are provided in the conclusion.

\section{Policy-Response Analysis}

To investigate dynamic dependencies among the variables and to assess the consequences of policy measures we conduct a response analysis with the estimated model. Specifically, we derive impulseresponses as well the responses to specific policy measures. The policy measures at hand are a tax on the consumption of high-carbon intensive goods and a subsidy on the consumption of low-carbon intensive goods.

Impulse response functions generally indicate how the endogenous variables respond to external influences. In a VAR model, where all variables are endogenous, the only external inputs are the disturbances, which amount to one-step-ahead prediction errors. They are "innovations" or "surprises," such as "policy shocks," which cannot by explained by the model and past data. We 
translate the instrument of a carbon tax into a negative growth shock for the HCIS while a subsidy for the LCIS is interpreted as a positive growth shock to all industries in this sector.

Using the lag operator, $L$, defined by $L y_{t}=y_{t-1}$, we can express the VAR process (1) as $A(L) y_{t}=\varepsilon_{t},{ }^{4}$ with $A(L)=I-A L$. The infinite moving average representation, given by

$$
y_{t}=A^{-1}(L) \varepsilon_{t}=\tilde{C}(L) \varepsilon_{t}, \quad \operatorname{Cov}\left(\varepsilon_{t}\right)=\Sigma,
$$

captures the responses of the $y$-variables with respect to the prediction errors, $\varepsilon_{t}$. Here, $\tilde{C}(L)=$ $\tilde{C}_{0}+\tilde{C}_{1} L+\tilde{C}_{2} L^{2}+\ldots$ is, in general, a matrix polynomial of infinite order. ${ }^{5}$ The $i, j$-element of $\tilde{C}_{k}, \tilde{c}_{k, i j}$, can be interpreted as the change in the $i$-th component in $y_{t+k}$ due to a unit shock in the $j$-th innovation in vector $\varepsilon_{t}$ at time $t$.

However, the prediction error $\varepsilon_{j t}$ is not necessarily uniquely associated with a shock to $y_{j t}$ in the same period. To have a unique association we have to make sure that the shocks are uncorrelated. In linear VAR analysis, this can be achieved by regarding $\varepsilon_{t}$ as being some linear combination of "structural" shocks, denoted by $u_{t}$, such that

$$
\varepsilon_{t}=R u_{t}
$$

A common strategy is to obtain the Choleski decomposition of the covariance matrix of the prediction errors, $\Sigma$, i.e.,

$$
\Sigma=R R^{\prime}
$$

where $R$ is a lower triangular matrix with positive diagonal elements. Transformation $u_{t}=R^{-1} \varepsilon_{t}$ is also called an orthogonalization of the prediction errors, because the components of $u_{t}$ are uncorrelated and have unit-variance, i.e., $\operatorname{Cov}\left(u_{t}\right)=I$, since

$$
\left.\mathrm{E}\left(u_{t} u_{t}^{\prime}\right)=\mathrm{E}\left[R^{-1} \varepsilon_{t} \varepsilon_{t}^{\prime-1}\right)^{\prime}\right]=R^{-1} \Sigma\left(R^{-1}\right)^{\prime}=I .
$$

Interpreting vector $u_{t}$ as the structural innovations driving the process, i.e.,

$$
y_{t}=\tilde{C}(L) \varepsilon_{t}=\tilde{C}(L) R u_{t}=C(L) u_{t} .
$$

the structural impulse response function can be derived from the moving average coefficients by

$$
C_{k}=\tilde{C}_{k} R \text {. }
$$

Note that the derivation of the structural shocks, $u_{t}$, via Choleski decomposition places specific assumptions on the contemporaneous influence of the structural shocks on the endogenous variables. In our specification, with ordering $y_{t}=\left(\text { out }_{h i, t}, \text { out }_{l o, t}, e m p_{h i, t}, e m p_{l o, t}\right)^{\prime}$, a lower-triangular $R$ implies that structural shocks to high-carbon intensive output immediately affects hight-carbon intensive output, low-carbon intensive output, high-carbon intensive employment and low-carbon intensive employment. A shock to the low-carbon intensive sector output has, however, no simultaneous impact on the high-carbon intensive sector, which reacts only with a delay of one period, but has an immediate affect on high-carbon intensive and low-carbon intensive employment.

\footnotetext{
${ }^{4}$ To simplify the notation, we omit the constant term, $c$, as it does not enter the dynamics of the process.

${ }^{5}$ We use superscript $\varepsilon$ to refer to response coefficients and with respect to the prediction error.
} 
Our estimates for VAR-coefficient matrix $A$, given above, and $R$,

$$
\hat{R}_{U S A}=\left[\begin{array}{cccc}
2.3817 & 0 & 0 & 0 \\
1.0317 & 2.5179 & 0 & 0 \\
0.7559 & 0.3836 & 0.6283 & 0 \\
1.2145 & 0.9203 & 0.4872 & 0.5982
\end{array}\right]
$$

give rise to the impulse responses, $\hat{C}, k=0,1, \ldots 10$, shown in Figure 1 . Clearly, in view of the small sample size, the results reported here can only be indicative. Interval estimation and significance testing, prevented by sample-size limitations, would be required for more definite conclusions. However, rather than producing erratic responses, as is often the case if the number estimated parameters is very high relative to the number of observations, response analysis discussed below yields smooth and plausible response estimates.

The plots indicate that all endogenous variables respond to impulses over a period of about five years at most, after which they decay to zero. In the following, we briefly discuss the point estimates of the unit-impulse responses, i.e., the responses due to positive growth shocks with a size of one percent.

For a one-percent-shock to output of the high-carbon intensive sector we have the following responses. It has only an immediate impact to the sector itself; there is almost no effect after one year and beyond. The low-carbon intensive sector also experiences a simultaneous benefit in that it growths by about $0.2 \%$, an effect that become negative after one year and then decays after two to three yeasr. Employment in both sectors increases after one year by $0.3 \%$ in the HCIS and by $0.5 \%$ in the LCIS; this effect vanishes after three to five years.

A shock to the output in the LCIS has, due the identification restrictions in place, no immediate impact on the high-carbon intensive sector, but causes the high-carbon intensive sector to grow by about $0.21 \%$ percent after one year, by $0 \%$ after two years, by $-0.12 \%$ after 2 years and virtually no effect after that. The impact on the low-carbon intensive sector itself remains positive for the first two years after which it vanishes. Employment in HCIS sector increases slightly by $0.15 \%$ in the year of the shock and then increases to $0.21 \%$ in the second year. The positive response drops to zero at year four and thereafter. The effect of the shock on employment in the LCIS is similar but with an increased growth of $0.36 \%$ in the first year and 0.42

A shock to employment in the HCIS lowers output growth in the high-carbon intensive (lowcarbon intensive) sector by about $0.5 \%(0.65 \%)$ after one year. The negative consequences disappear after approximately four to five years. After the initial shock, high-carbon intensive employment growthquickly returns to zero after 2 years.the second year and zero thereafter. The impact on employment in the LCIS is quite strong with $0.77 \%$ in the first year but the decays to zero after.

A shock to employment in the LCIS lowers output growth in the high-carbon intensive (lowcarbon intensive) sector by about $0.92 \%(0.54 \%)$ after one year. The negative consequences disappear after two years years in both sectors. After the initial shock, high-carbon intensive employment growth becomes slightly negative and then positive before the effect dies out after two to three years. The low-carbon intensive employment growth becomes slightly negative after the initial shock and 
then positive before it decays to zero after the four to five years.
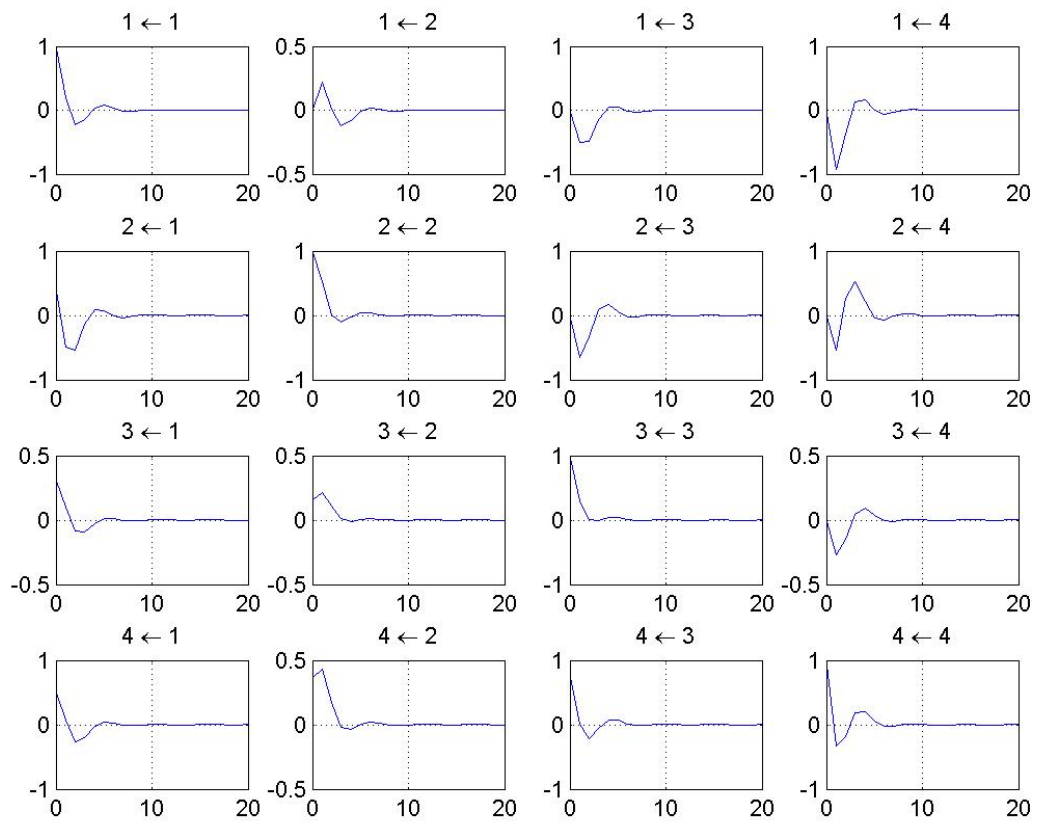

Figure 1: Impulse-response functions from the estimated $\operatorname{VAR}(1)$ model (1) with $y_{t}=$

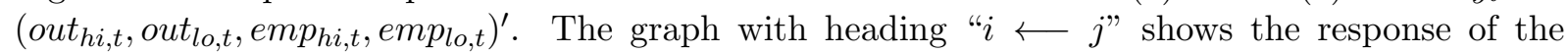
$i$ th variable in $y_{t}$ due to an unit impulse to structural shock $j$.

To assess the cumulative effects, Figure 2 shows the cumulative-response functions, computed by

$$
\bar{C}_{k}=\sum_{i=0}^{k} C_{i}
$$

The cumulative long-term effect of a one-percent shock to high-carbon intensive sector growth are as follows. The cumulative response of the high-carbon intensive sector itself remains virtually at the initial shock level (0.94\%); the low-carbon intensive sector experiences a decrease of about $0.6 \%$; and employment in both sectors reacts with positive growth of about $0.2 \%$ (HCIS) and $0.14 \%$ (LCIS) cumulatively. Thus, the effect on employment growth is slightly stronger in the high-carbon intensive sector. A shock to the low-carbon intensive growth induces basically no cumulative highcarbon intensive growth; the low-carbon intensive sector itself responds with an increase of about $1.49 \%$; and employment in both sectors responds positively with growth of about $0.5 \%$ (HCIS) and $0.94 \%$ (LCIS).

The cumulative long-term effects of an employment shock to the HCIS are negative on output in both sectors with about $-1.0 \%$ and $-0.7 \%$. In terms of employment, the initial $1 \%$ shock increases 
to $1.4 \%$ employment growth in the high-carbon intensive sector and to $0.6 \%$ in the low-carbon intensive sector. Finally, a shock to employment in the LCIS results in cumulative responses of $-1.0 \%$ output growth in the high-carbon intensive sector and $0.37 \%$ in the low-carbon intensive sector. Employment in the HCIS is negatively affected by this shock (-0.25\%). Cumulative employment growth in the LCIS itself is about $0.9 \%$.
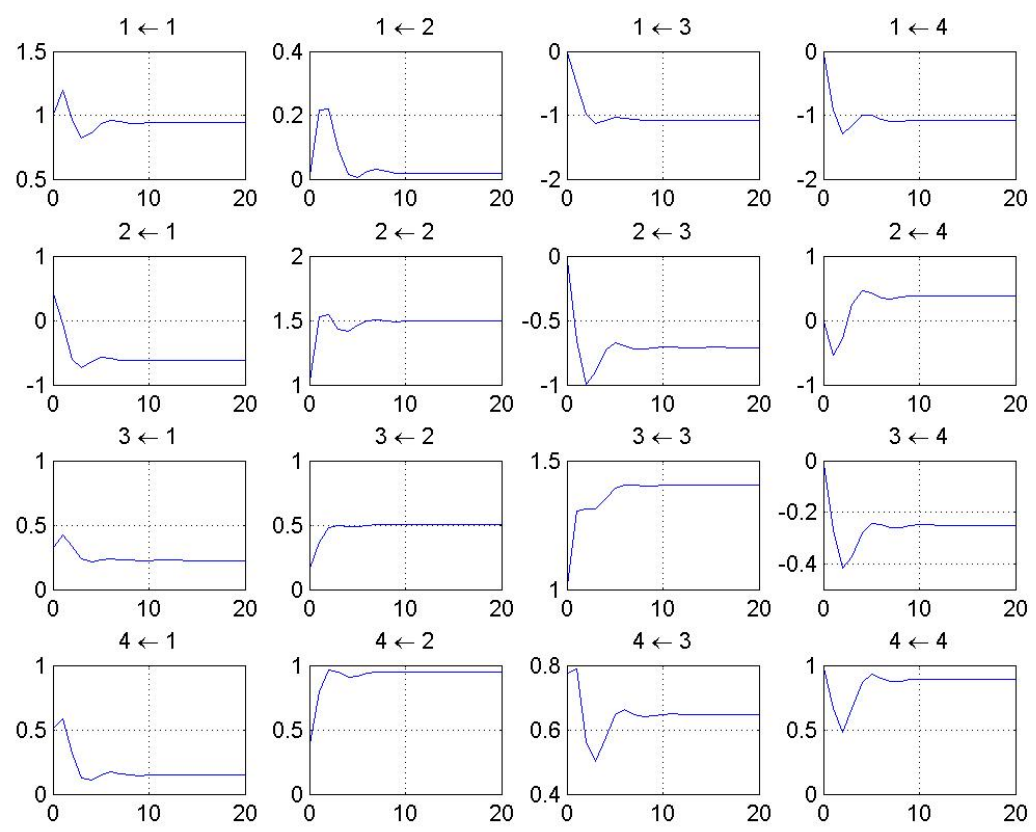

Figure 2: Cumulative-response functions from estimated VAR(1) model (1) with $y_{t}=$ $\left(\text { out }_{h i, t}, \text { out }_{l o, t}, e m p_{h i, t}, e m p_{l o, t}\right)^{\prime}$. The graph with heading " $i \longleftarrow j$ " shows the response of the $i$ th variable in $y_{t}$ due to an unit impulse to structural shock $j$.

\subsection{Policy-Experiments}

\section{Carbon Tax and Subsidy}

We start with the case in which a tax is levied on the goods of the high-carbon intensive sector and a subsidy is paid on the consumption of low-carbon intensive goods. We are interested in the effects of such a policy on employment and output.

Within the scope of impulse-response analysis, we model such a policy as particular policy shock which combines a positive shock to the LCIS sector by granting, for example, some form subsidies or tax relief, with a negative shock to the high-carbon intensive sector by a reduction of existing subsidies or by imposing additional taxes, such that the latter finances the former. Specifically, we calculate the cumulative effects on employment in both sectors by shifting shifting the amount equivalent to $1 \%$ of the gross output (base year 2005) of the HCIS from the HCIS to the LCIS. In 
the case of the United States, this amounts to a tax or subsidy cut in the amount of EUR 86.5 billion (in real 1995 USD) which is imposed on the HCIS and immediately transferred to the LCIS. The relief of the LCIS could come in the form of a tax cut, a direct subsidy or some other type of direct or indirect support to the low-carbon intensive sector. We can not distinguish specific policy instruments with our method.

Technically, we impose a simultaneous one-time growth shock on both sectors: The output growth of the HCIS is reduced by $1 \%$ in the period of the shock and the output growth rate of the LCIS is boosted with a growth rate equivalent to the collected tax revenue from the HCIS (generally not 1\%) In level terms, such a nonrecurring growth shock results in a permanent increase (decrease) of output in the LCIS (HCIS). Thus, our policy experiment assumes that the policy is upheld for all years after the shock, that for example the tax on the HCIS and the corresponding subsidy to the LCIS is permanent, and not abolished after the first year.

The cumulative effect of such a combined shock on employment, as shown in Figure 3, is positive. Employment growth is negative in the first year in both sectors but becomes positive quickly with about $0.75 \%$ in the LCIS and close to $0.25 \%$ in the HCIS. The growth effect on total employment lies at roughly $0.47 \%$ and is reached in less than 5 years.

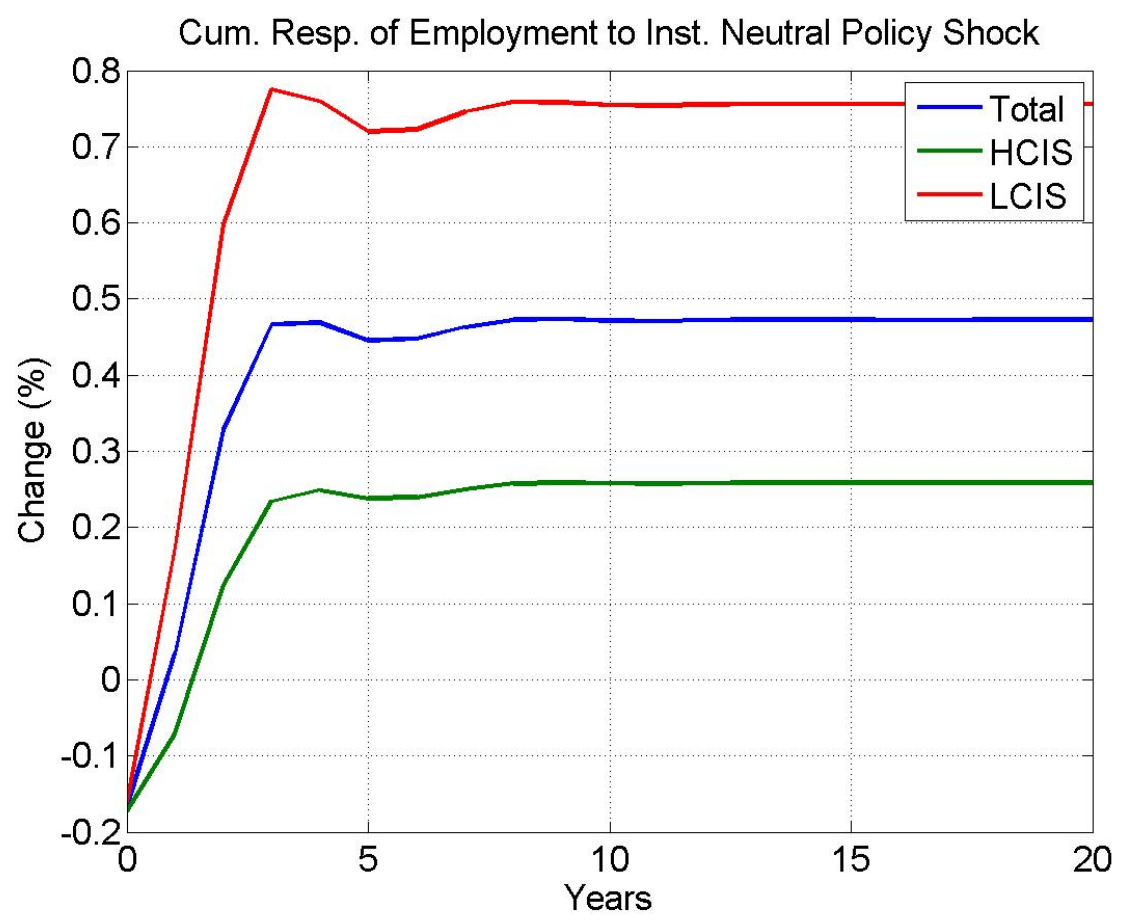

Figure 3: Cumulative-response of aggregate employment and sector employment due to an instantaneously budget-neutral policy shock.

Another question is whether the positive effect on employment is accompanied by a long-run drop in gross output. This, however, is not the case, as the cumulative joint response estimates (shown in Figure 4 ) indicates. Total gross output drops initially by about $0.2 \%$, but increases within 
two years to over $0.5 \%$. As one may expect, the output growth of the HCIS remains negatively affected by our policy while the additional output growth of the LCIS is more than $2 \%$ higher after 5 years than in the business as usual scenario (BAU). Thus, the policy promotes or accelerates a structural change towards a low-carbon intensive economy.

It should be emphasized that these cumulative growth effects are relative to the BAU: A reduction of growth by $1 \%$ in the HCIS after 5 years means that the total output growth in the HCIS after 5 years is approximately $1 \%$ lower than in a scenario in which no policy is implemented. A $1 \%$ reduction after 5 years translates into an annual reduction of growth of about $0.2 \%$. The actual annual growth rate in the HCIS can still be positive but would be $0.2 \%$ lower if the policy is introduced.

In summary, our response analysis suggest that green policies, which favor the U.S. low-carbon intensive sector at the expense of the high-carbon intensive sector, result in both, employment and output growth. Note again that the policy is strictly budget neutral and finances itself. The results for the other countries are presented at the end of Appendix 3 and in Section 4.2. We can, however, not observe the positive effects on total output and total employment for all countries.

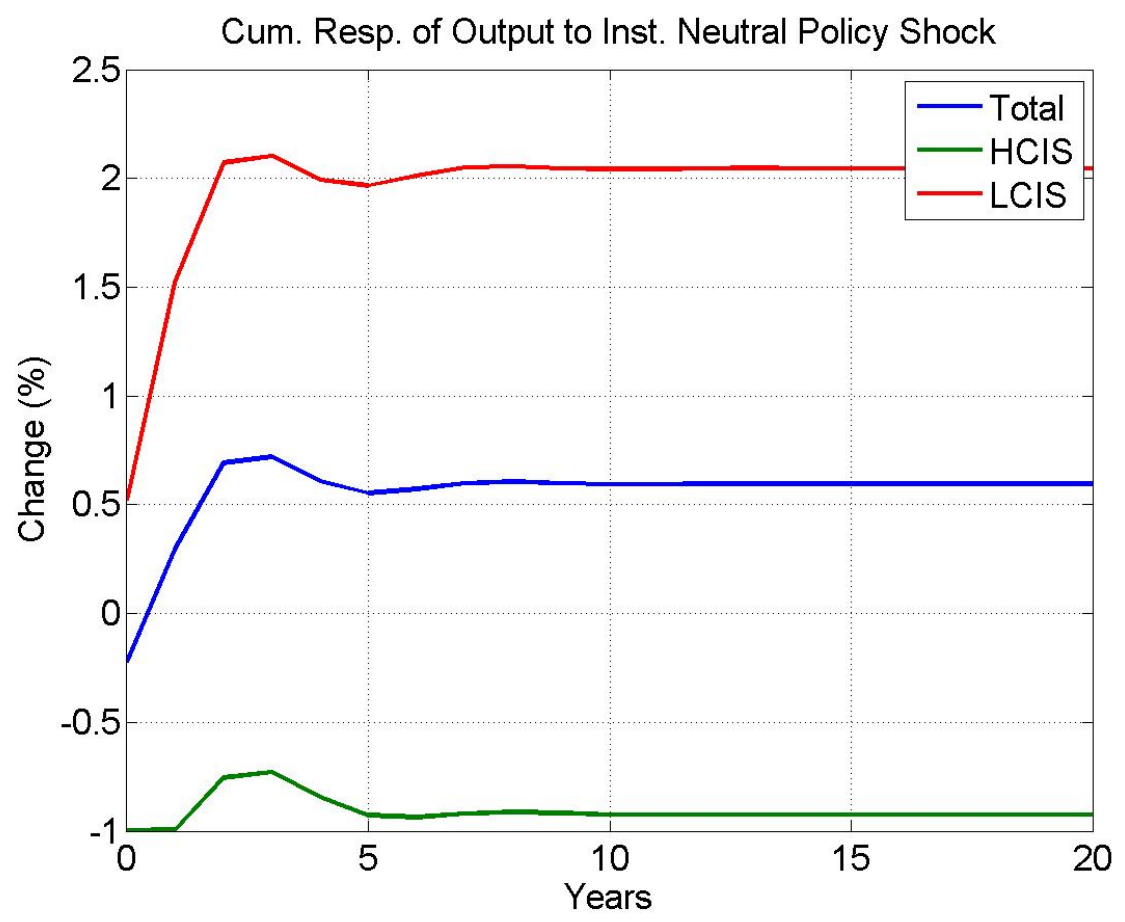

Figure 4: Cumulative-response of aggregate output and sector due to an instantaneously growthsneutral policy shock. 
Table 2: Summary Statistics (USA)

\begin{tabular}{lrrrr}
\hline \hline & out $_{h i, t}$ & out $_{l o, t}$ & emp $_{h i, t}$ & emp $_{l o, t}$ \\
\hline Mean & 2.47 & 3.09 & 1.39 & 1.72 \\
\hline out $_{h i, t}$ & 16.32 & 3.32 & 2.02 & 3.61 \\
out $_{l o, t}$ & 0.39 & 11.00 & 2.11 & 5.04 \\
emp $_{h i, t}$ & 0.65 & 0.51 & 1.52 & 2.30 \\
emp $_{l o, t}$ & 0.68 & 0.72 & 0.89 & 4.39 \\
\hline \hline
\end{tabular}

Bottom panel: Variances (diagonal elements), covariances (above-diagonal elements), and correlations (belowdiagonal elements) 


\section{Carbon Tax - No Subsidy}

As a next case, we discuss the scenario of a carbon tax that is levied on the HCIS. This time, no subsidy is given to the LCIS. Technically, we shock the system by imposing a negative growth shock on output of the HCIS. The cumulative response of employment is given in Figure 5. We can see that the positive impact on employment that we could observe in the previous case disappears. Employment in both sectors decreases. In total, we estimate a reduction of employment of roughly $0.4 \%$ as compared to the BAU.

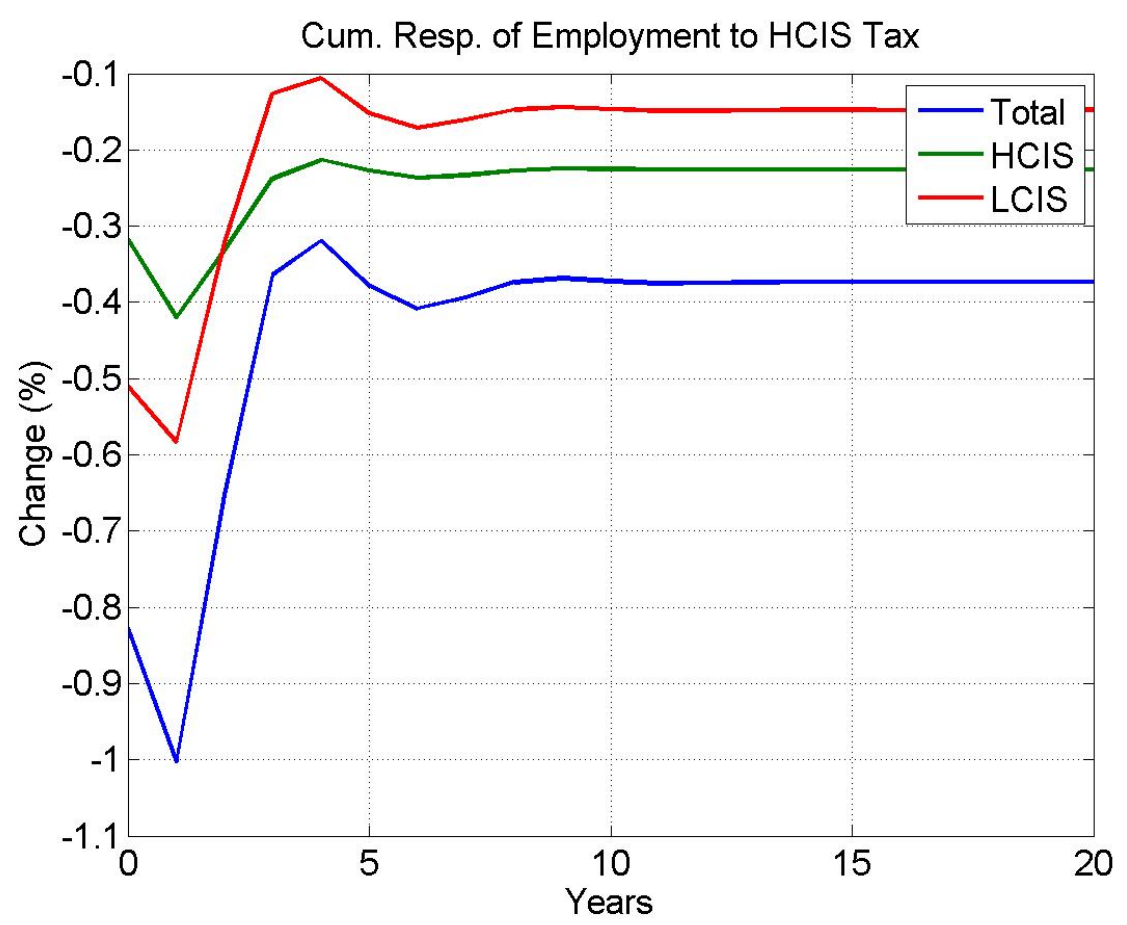

Figure 5: Cumulative-response of aggregate employment and sector employment due to a an isolated policy shock on the HCIS only.

Figure 6 shows the cumulative joint response estimates on gross output in both sectors as well as on total output. As in the case of employment, the effects on output vary. In the HCIS, output is reduced by almost $1 \%$ as compared to the BAU but output increases by approximately $0.6 \%$ in the LCIS. Total gross output can be expected to be almost $0.4 \%$ lower than in the BAU.

It is essential to keep in mind that in this policy scenario of an isolated negative growth shock to the HCIS, we have burdened one sector without injecting anything back into the system. This explains the negative results compared to to the previous policy experiment. In case of a tax, one may expect that the government uses the collected tax revenues for some purpose. This activity by the government may be stimulating growth in one or the other sector. This aspect is neglected here. However,these results also stress the importance of additional mitigating policies as an implemented carbon tax by itself - even if only imposed on one sector - has negative effects on output and employment. 


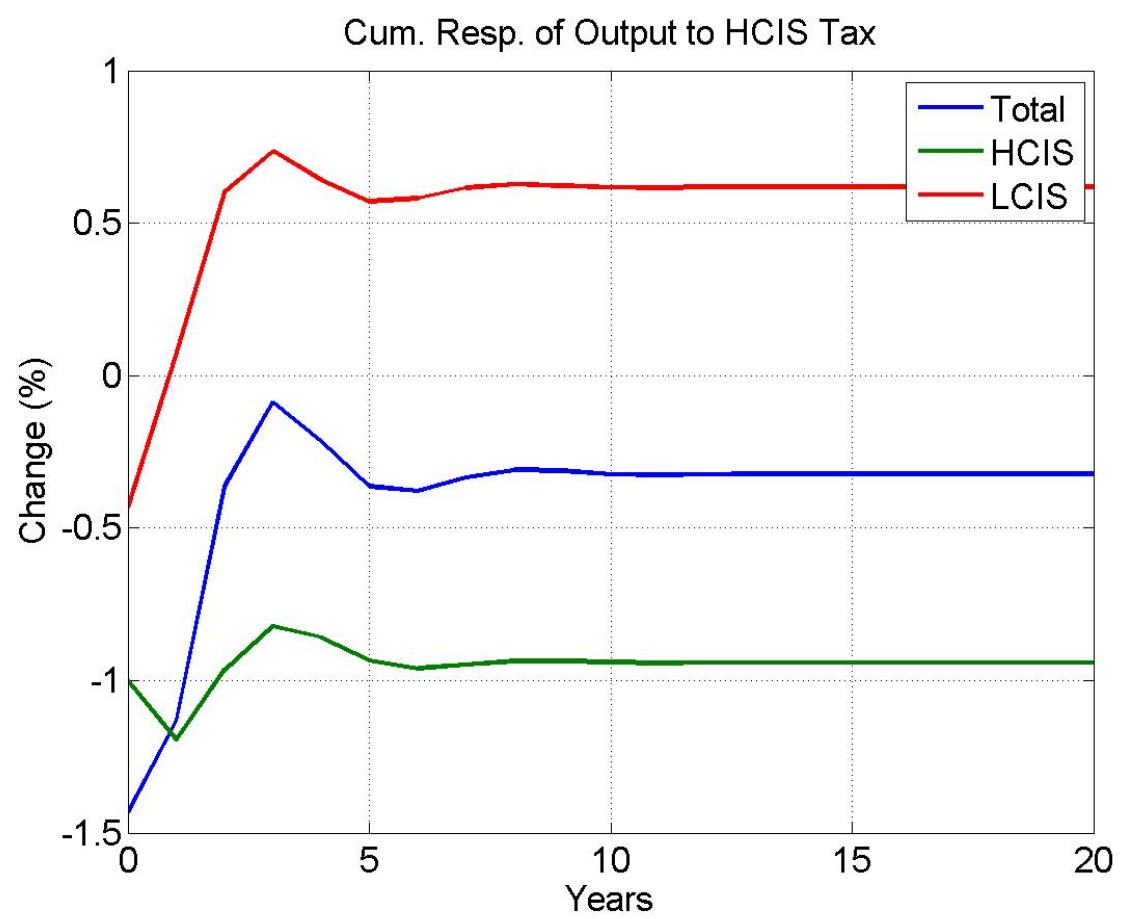

Figure 6: Cumulative-response of aggregate output and sector output due to a an isolated policy shock on the HCIS only.

\section{Carbon Tax and Wage Subsidy}

Finally, we estimate the effects of a shock on the HCIS if a wage subsidy is given to both sectors. As noted previously, our method does not allow for an estimation of effects of specific policy instruments as for example a wage subsidy. We can, however, account for a general wage subsidy by adjusting the shock size for both sectors. We assume that the wage subsidies are entirely financed through the tax levied on the HCIS. Furthermore, we assume that the subsidy is distributed between the two sectors according to the relative size of the two sectors in terms of employment. Thus, in addition to the $1 \%$ negative output growth shock on the HCIS, we impose two simultaneous positive growth shocks on both sectors which correspond in total size to the negative shock (budget neutrality) and are allocated according to the relative size of employment in the two sectors. Thus, some portion of the $1 \%$ negative shock on the HCIS is mitigated and the positive shock on the LCIS depends on the relative size of LCIS employment.

We depict the cumulative response of employment in Figure 7 and output in Figure 8. One can clearly see in both graphs that this budget neutral policy scenario is just a linear transformation of case 1 whereby the strength of the shock vector is scaled down. The effects are therefore similar to case 1 but are less strong. 


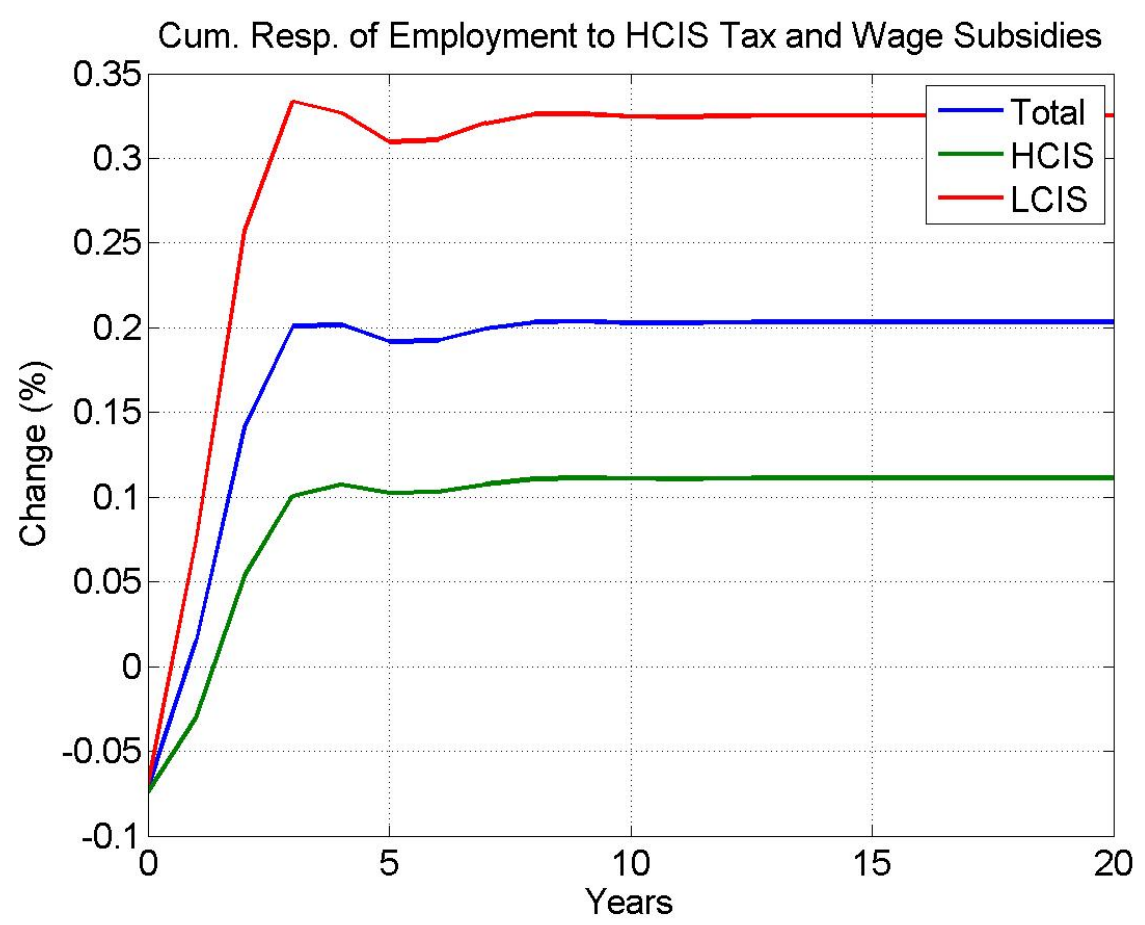

Figure 7: Cumulative-response of employment due to a a tax on the HCIS and wage subsidies to both sectors.

\subsection{Overview of Country Results}

In the following, we present an overview of the results of our impulse response analysis for all nine countries examined. Detailed statistics for all countries can be found in the appendix. We focus on case 1 (carbon tax and a subsidy) because it is a budget neutral policy and the skimmed tax revenues are reinjected back into the economy. Table 5 shows the effects on total real gross output and employment relative to the BAU scenario after 5 years and Table 5 summarizes the effects after 10 years. We note that the results do basically not change anymore after 5 years. Our policy has no further impact on output and employment. In the discussion, we therefore only refer to Table 5 .

We can see that the results of the policy differ among countries. Consistently, output growth is boosted in the LCIS while it is slowed down in the LCIS. At this point, we remind ourselves that the growth rates given in tables are to be interpreted as deviations from the total growth of the BAU scenario. The actual growth rates can be positive or negative (For output at least, we would usually assume to have positive growth rates over 5 years). We observe slight total output growth for some countries and slight negative total output growth for others. Overall, the imposed climate policiy does not have a huge effect on total gross output and total employment. Exceptions are Australia and Hungary. In Australia, the policy leads to a decrease of output growth in the amout of approximately $1 \%$ (corresponds to an annual gross output decrease of about $0.2 \%$ ) and decrease in employment of about 1.6\%. (annual decrease of about $0.32 \%$ ). An opposite situation is 


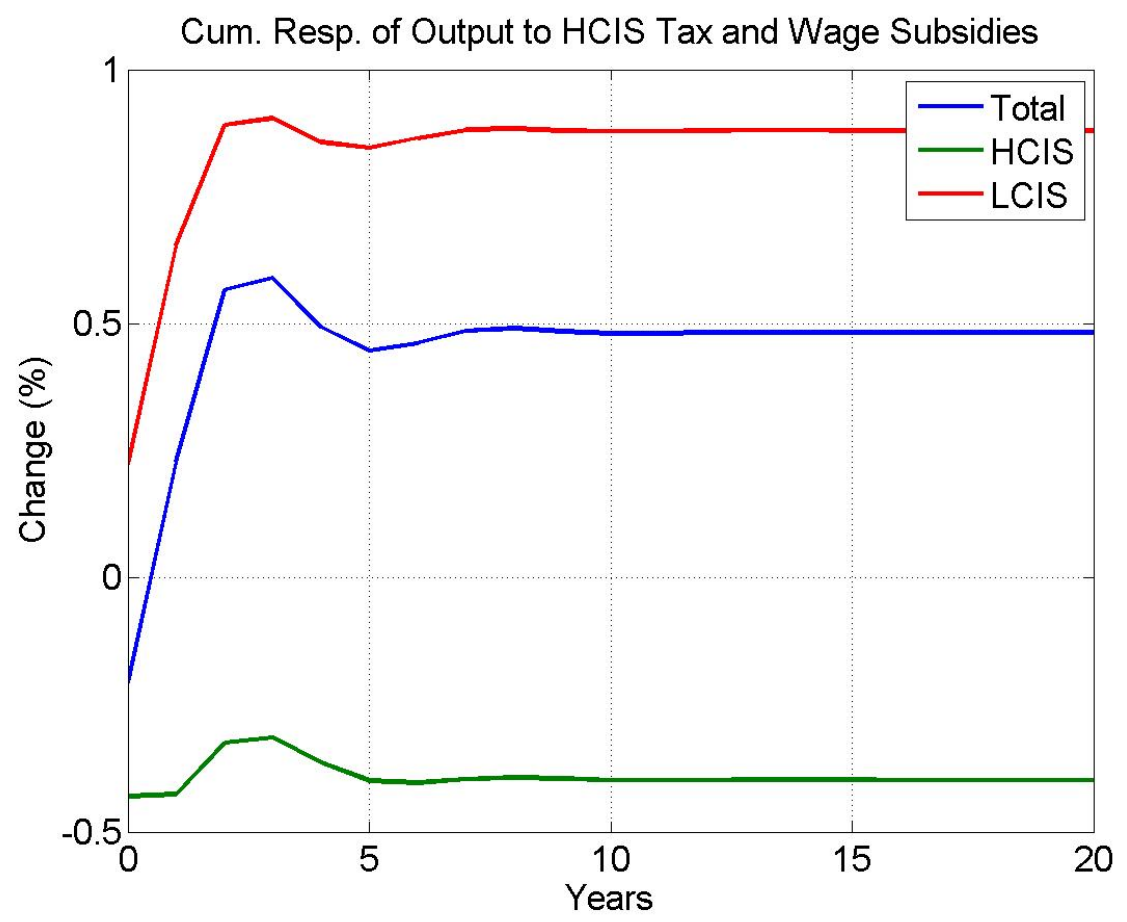

Figure 8: Cumulative-response of output due to a a tax on the HCIS and wage subsidies to both sectors.

found in Hungary where the climate policy boosts the economy by $2.31 \%$ in terms of gross output (annual increase of about $0.46 \%$ ) and an increase of employment growth of more than $0.9 \%$ (annual increase of about $0.18 \%)$.

In general, we can also oberve that additional output growth and additional employment growth usually move into the same direction, i.e. these growth rates are either both positive or both negative. This is, however, not true for individual sector output and employment growth. Here we can see that sometimes positive gross output growth is accompanied by negative employment growth. This occurs in both, the HCIS and the LCIS. In most countries, a one percent change of output growth in LCIS has a less strong effect on employment then a one percent change of output growth in the HCIS, suggesting that the average labor productivity in the LCIS sector is higher than in the HCIS. We can see this nicely in the cases of France and South Korea where the absolute value of the output growth effect in the HCIS and the LCIS are approximately the same. In France, the policy shock leads to an additional $+1.08 \%$ of output growth in the LCIS and $-1.02 \%$ in HCIS. Yet, employment in HCIS remains unaffected while employment growth in the LCIS is increased by only $0.32 \%$. This means that labor productivity must have increased in the LCIS while it decreased in the HCIS. ${ }^{6}$ In South Korea, the situation is similar with almost identical changes of output in absolute terms for both sectors (HCIS $-0.73 \%$, LCIS $+0.69 \%$ ). Again, employment in the LCIS responds not very strongly to the output increase in LCIS resulting again in a higher labor productivity increase in the LCIS. In the HCIS, the decrease of output of $0.73 \%$ is accompanied by an employment decrease of "only" $0.19 \%$ implying a decrease of average labour productivity in the

\footnotetext{
${ }^{6}$ We are loosely interpreting the ratio of gross output over employment as "labor productivity" here.
} 
HCIS. The same phenomenon can be observed for the HCIS and LCIS in all other countries. Such a decrease of labor procitivity in the HCIS could occur if highly productive industries reduce their output stongly and lay off workers that then work in less productive industries within the HCIS.

We must keep in mind that we are dealing with gross output and not value added or GDP. So, the ratio output over labor might not serve well as a good indicator for labor productivity. Value added would be more appropriate. However, an estimation of average labour productivities in the HCIS and the LCIS by taking value added over engaged workers confirms the above results: The LCIS is on average more productive than the HCIS. The positive total employment effects that we found for several countries (Germany, France, Hungary and United States) must therefore come from the higher growth dynamics of the LCIS that are triggered by the policy shock. In all cases with positive employment growth, the shock kicked of a much stronger positive growth dynamic in the LCIS than it slowed down growth in the HCIS. This effect overcompensates the effect of higher labor productivity on total employment and results in a positive net effect on employment. Implementing policies that support the LCIS obviously support the more productive sector in the economy.

In summary, we find that the chosen double shock does not have a huge impact on the total level of output and employment. For the most part, structural adjustments are triggered and not reductions of economic activity as a whole. In several countries, like the U.S. or Hungary, we can see positive effects on total economic activity that are a little stronger than being closely around zero. For Australia, the effects are also somewhat stronger but on the negative side. The reasons for these differences on an individual country level not quite clear at this point. It is likely that also the initial condititions (for example sizes of the HCIS and LCIS in terms of output and employment) at the time of the shock or the differing sample sizes play a role.

\section{Conclusion}

Given the great urgency to implement effective climate policies to reduce global warming, a dynamic model with structural change and, related to that, concrete policy proposals of $\mathrm{CO}_{2}$ emission have been developed in this contribution. We consider three types of policies: 1) imposing a carbon tax on carbon intensive industries, 2) imposing a carbon tax and subsidizing labor (or reducing overhead cost for labor), and 3) imposing a carbon tax and subsidizing the less carbon intensive industries. We study the dynamics of output and employment resulting from each of these policy measures and their effects on structural change. In order to do so the carbon intensities of industries are computed and the empirical effects of policy measures are studied. The actual empirical evaluation of the carbon tax policies is undertaken by a double-sided VAR. As intuition might suggest, the least favorable outcome is obtained when only a carbon tax rate is imposed on carbon intensive industries and the revenue not used for other purposes such as reducing other tax rates, subsidizing wage or payroll tax or the development of other (less carbon intensive) products. Since our our proposed double-sided VAR allows us to permit budgetary neutrality we study the cases when the revenue is used for other purposes. The empirical results show that in particular the third policy measure where carbon taxes are used to subsidize the development of other products has the greatest net gains in terms of output and employment. 
Table 3: Employment and Output Data on Industry Level

\begin{tabular}{llcc}
\hline$\#$ & Country & Years & Observations \\
\hline & & & \\
1 & Germany & $1992-2005$ & 14 \\
2 & Australia & $1989-2005$ & 17 \\
3 & France & $1978-2005$ & 28 \\
4 & Hungary & $1992-2005$ & 14 \\
5 & Japan & $1973-2005$ & 33 \\
6 & South Korea & $1970-2005$ & 36 \\
7 & Sweden & $1970-2005$ & 36 \\
8 & United Kingdom & $1970-2005$ & 36 \\
9 & USA & $1970-2005$ & 36 \\
& & & \\
\hline
\end{tabular}

Table 4: Real Employment and Output Effects after 5 Years - Carbon Tax and Subsidy

\begin{tabular}{llcccccc}
\hline \# & Country & $\begin{array}{c}\text { HCIS } \\
\text { Employm. } \\
\text { Growth }\end{array}$ & $\begin{array}{c}\text { LCIS } \\
\text { Employm. } \\
\text { Growth }\end{array}$ & $\begin{array}{c}\text { Total } \\
\text { Employm. } \\
\text { Growth }\end{array}$ & $\begin{array}{c}\text { HCIS } \\
\text { Output } \\
\text { Growth }\end{array}$ & $\begin{array}{c}\text { LCIS } \\
\text { Output } \\
\text { Growth }\end{array}$ & $\begin{array}{c}\text { Total } \\
\text { Output } \\
\text { Growth }\end{array}$ \\
\hline & & & & & & & \\
2 & Germany & $0.29 \%$ & $0.08 \%$ & $0.19 \%$ & $-0.36 \%$ & $0.90 \%$ & $0.36 \%$ \\
3 & Australia & $-1.41 \%$ & $-2.26 \%$ & $-1.63 \%$ & $-1.79 \%$ & $0.42 \%$ & $-0.98 \%$ \\
4 & France & $0.00 \%$ & $0.32 \%$ & $0.15 \%$ & $-1.02 \%$ & $1.08 \%$ & $0.09 \%$ \\
5 & Jungary & $1.20 \%$ & $2.83 \%$ & $1.90 \%$ & $-0.11 \%$ & $4.52 \%$ & $2.31 \%$ \\
6 & South Korea & $-0.18 \%$ & $-0.56 \%$ & $-0.35 \%$ & $-1.04 \%$ & $0.20 \%$ & $-0.40 \%$ \\
7 & Sweden & $-0.19 \%$ & $-0.44 \%$ & $-0.27 \%$ & $-0.73 \%$ & $0.69 \%$ & $-0.12 \%$ \\
8 & United Kingdom & $-0.48 \%$ & $-0.13 \%$ & $-0.33 \%$ & $-0.34 \%$ & $0.99 \%$ & $0.35 \%$ \\
9 & United States & $0.24 \%$ & $-0.03 \%$ & $-0.08 \%$ & $-1.19 \%$ & $0.24 \%$ & $-0.45 \%$ \\
& & $0.72 \%$ & $0.45 \%$ & $-0.93 \%$ & $1.97 \%$ & $0.55 \%$ \\
\hline
\end{tabular}

Relative to BAU scenario after 5 years 
Table 5: Real Employment and Output Effects after 10 Years - Carbon Tax and Subsidy

\begin{tabular}{|c|c|c|c|c|c|c|c|}
\hline$\#$ & Country & $\begin{array}{c}\text { HCIS } \\
\text { Employm. } \\
\text { Growth }\end{array}$ & $\begin{array}{c}\text { LCIS } \\
\text { Employm. } \\
\text { Growth }\end{array}$ & $\begin{array}{c}\text { Total } \\
\text { Employm. } \\
\text { Growth }\end{array}$ & $\begin{array}{c}\text { HCIS } \\
\text { Output } \\
\text { Growth }\end{array}$ & $\begin{array}{c}\text { LCIS } \\
\text { Output } \\
\text { Growth }\end{array}$ & $\begin{array}{c}\text { Total } \\
\text { Output } \\
\text { Growth }\end{array}$ \\
\hline 1 & Germany & $0.28 \%$ & $0.07 \%$ & $0.18 \%$ & $-0.37 \%$ & $0.88 \%$ & $0.34 \%$ \\
\hline 2 & Australia & $-1.41 \%$ & $-2.26 \%$ & $-1.63 \%$ & $-1.79 \%$ & $0.42 \%$ & $-0.99 \%$ \\
\hline 3 & France & $0.01 \%$ & $0.26 \%$ & $0.11 \%$ & $-1.03 \%$ & $0.96 \%$ & $0.02 \%$ \\
\hline 4 & Hungar. & $1.25 \%$ & $2.81 \%$ & $1.92 \%$ & $-0.09 \%$ & $4.53 \%$ & $2.33 \%$ \\
\hline 5 & Japan & $-0.18 \%$ & $-0.56 \%$ & $-0.35 \%$ & $-1.05 \%$ & $0.21 \%$ & $-0.40 \%$ \\
\hline 6 & South Korea & $-0.19 \%$ & $-0.45 \%$ & $-0.27 \%$ & $-0.74 \%$ & $0.69 \%$ & $-0.12 \%$ \\
\hline 7 & Sweden & $-0.48 \%$ & $-0.13 \%$ & $-0.33 \%$ & $-0.35 \%$ & $0.98 \%$ & $0.34 \%$ \\
\hline 8 & United Kingdom & $-0.12 \%$ & $-0.03 \%$ & $-0.08 \%$ & $-1.19 \%$ & $0.24 \%$ & $-0.45 \%$ \\
\hline 9 & United States & $0.26 \%$ & $0.75 \%$ & $0.47 \%$ & $-0.92 \%$ & $2.04 \%$ & $0.59 \%$ \\
\hline
\end{tabular}

Relative to BAU scenario after 10 years 


\section{Appendix:}

Kato, Semmler, and Samaan (2010) suggest a three sector growth model which allows for structural change on a balanced growth path. Consumption goods are either high-carbon intensive and are produced by the high-carbon intensive sector $(\mathrm{H})$, or they are low-carbon intensive and are produced by the low-carbon intensive sector $(\mathrm{L})$. The third sector is the capital goods sector whose carbon-intensity is not further considered. In the baseline version of the model, i.e. without climate change policies, a representative household chooses an optimal consumption path according to its preferences described by a CRRA (constant relative risk aversion) utility function:

$$
U_{t}=\int_{0}^{\infty} e^{-\rho t} \frac{\left[H_{t}^{\beta} L_{t}^{\theta}\right]^{1-\sigma}-1}{1-\sigma} d t
$$

where the parameters $\rho, \beta, \theta, \sigma$ are all strictly positive.

The three sectors have identical, neoclassical production functions with constant returns to scale. Two production factors (capital and labor) exist and technical change is assumed to be labor augmenting. Under the conditions of perfect competition, it can then be shown that the per-efficiency labor budget constraint is equal to:

$$
\dot{k}_{t}+\left(g_{t}+\delta\right) k_{t}+P_{H} h_{t}+P_{L} l_{t}=B_{K} F\left(k_{t}, 1\right) .
$$

The households consumtion choice can be transformed into a dynamic constrained optimization problem: Maximization of (5) subject to (6), after rewriting the utility function using per-efficiencylabor variables.

Solving this problem gives us the time paths of output and employment of the three sectors. It is shown in the paper, that the implementation of different climate change policies (the three policy scenarios correpsonding to the ones in this handbook contribution) lead to balanced growth paths in which the relative size of the two sectors $\mathrm{H}$ and L change. Output and employment shares in the $\mathrm{H}$ sector decrease over time while outout and employment in the $\mathrm{L}$ sector increase. 


\section{References}

Anderson, S., And P. Ekins (eds.) (2009): Carbon Energy Taxation - Lessons from Europe. Oxford University Press, Oxford, New York.

Babiker, M., And R. S. Eckaus (2007): "Unemployment Effects of Climate Policy," Environmental Science and Policy, 10, 600-609.

Babiker, M. H., J. M. Reilly, M. Mayer, R. S. Eckaus, I. S. Wing, and R. C. HyMAN (2001): "The MIT Emissions Prediction and Policy Analysis (EPPA) Model: Revisions, Sensitivities, and Comparisons of Results," Report No. 71.

Bach, S., C. Bork, M. Kohlhaas, C. Lutz, B. Meyer, B. Praetorius, and H. Welsch (2001): Die oekologische Steuerreform in Deutschland - Eine modellgestuetzte Analyse ihrer Wirkungen auf Wirtschaft und Umwelt. Springer Verlag, Heidelberg.

Barker, T., S. Junankar, H. Pollitt, and P. Summerton (2009): "The Effects of Environmental Tax Reform on International Competitiveness in the European Union: Modelling with E3ME," in Carbon Energy Taxation - Lessons from Europe, pp. 147-215. Oxford University Press, Oxford.

Boehringer, C., And R. Schwager (2003): "Die Oekologische Steuerreform in Deutschland: ein umweltpolitisches Feigenblatt," Perspektiven der Wirtschaftspolitik, 4(2), 211-222.

Bovenberg, L., And R. De Mooij (1994): "Environmental Levies and Distortionary Taxation," The American Economic Review, 84.

Bovenberg, L., and F. van Der Ploeg (2002): "Consequences of Environmental Tax Reform for Involuntary Unemployment and Welfare," in Handbook of Public Economics, Volume 3, pp. 1471-1545. Elsevier, Amsterdam.

Carraro, C., M. Galeotti, and M. Gallo (1996): "Environmental Taxation and Unemployment: Some Evidence on the Double Dividend Hypothesis in Europe," Journal of Public Economics, 62(1-2), 141-181.

Chateau, J., A. Saint-Martin, and T. Manfredi (2011): "Employment Impacts of Climate Change Mitigation Policies in the OECD - A General Equilibrium Perspective," Discussion paper, OECD.

Cherney, H. (1960): "Patterns of Industrial Growth," American Economic Review, 50, 624-654.

Clark, C. G. (1940): The Conditions of Economic Progress. MacMillan, London.

Dales, J. (1968): Pollution, Property and Prices. University of Toronto Press, Toronto.

Ekins, P., And S. Speck (eds.) (2011): Environmental Tax Reform - A Policy for Green Growth. Oxford University Press, Oxford, New York.

Fisher, A. G. (1935): The Clash of Progress and Security. MacMillan, London.

Frohn, J., P. Chen, B. Hillebrand, W. Lemke, C. Lutz, B. Meyer, and M. Pullen (2003): Wirkungen umweltpolitischer Massnahmen - Abschaetzung mit zwei oekonometrischen Modellen. Physica-Verlag, Heidelberg. 
Fuchs, V. (1968): The Service Economy. Columbia University Press, New York.

Goulder, L. H. (1994): "Energy Taxes: Traditional Efficiency Effects and Environmental Implications," in Tax Policy and the Economy 8, pp. 105-158. MIT Press, Cambridge Massachusetts.

(1995a): "Effects of Carbon Taxes in an Economy with Prior Tax Distortions: An Intertemporal General Equilibrium Analysis," Journal of Environmental Economics and Management, 29, 271-297.

(1995b): "Environmental Taxation and the "Double Dividend": A Reader's Guide," International Tax and Public Finance, 2(2), 157-183.

Greiner, A., L. Gruene, And W. Semmler (2010): "Growth and Climate Change: Thresholds and Multiple Equilibria," Dynamic Modeling and Econometrics in Economics and Finance, 12, $63-77$.

Greiner, A., And W. Semmler (2008): The Global Environment, Natural Resources and Economic Growth. Oxford University Press, Oxford.

Hansen, J. (2008): "Tipping point: Perspective of a climatologist," in In State of the Wild 20082009: A Global Portrait of Wildlife, Wildlands, and Oceans., pp. 6-15. Island Press.

Heady, C. J., A. Markandya, W. Blyth, J. Collingwood, and P. G. Taylor (2000): "The Role of Carbon Tax in Adjusting to Global Warming," .

IPCC (2006): IPCC Fourth Assessment Report: Climate Change 2006. Intergovernmental Panel on Climate Change, United Nations.

(2007): IPCC Fourth Assessment Report: Climate Change 200\%. Intergovernmental Panel on Climate Change, United Nations.

Kaldor, N. (1957): "A Model of Economic Growth," The Economic Journal, 67, 591-624.

Kaplow, L. (2008): The Theory of Taxation and Public Economics. Princeton University Press, Princeton, Oxford.

Kato, M., W. Semmler, and D. Samaan (2010): "Economics of Climate Change in a Generalized Balanced Growth Model," Discussion Paper.

Kuznets, S. (1957): "Quantitative Aspects of the Economic Growth of Nations: II," Economic Development and Cultural Change, 5, 3-111.

Lutz, C., And B. Meyer (2008): "Modellgestuetzte Simulationsrechnungen der GWS zu Energieund Klimaschutzfragen," GWS Discussion Paper 2001/1 ISS 1867-7290.

Mankiw, N. G. (2007): "One Answer to Global Warming: A New Tax," The New York Times, 07/16/09.

Meyer, B. (2005): "The Economic Environmental Model PANTA RHEI and its Application," GWS Discussion Paper 2005.

Meyer, B., A. Bockermann, G. Ewerhard, and C. Lutz (1999): Marktkonforme Umweltpolitik - Wirkungen auf Luftschadstoffemissionen, Wachstum und Struktur der Wirtschaft. PhysicaVerlag, Heidelberg. 
Nielsen, S., L. Pedersen, and P. Sorensen (1995): "Green Tax Reform, Unemployment and Endogenous Growth," International Tax and Public Finance.

Nordhaus, W. (2008): A Question of Balance. Princeton University Press, Princeton.

OECD (1978): Employment and Environment. OECD, Paris.

(1997): Environmental Policies and Employment. OECD, Paris.

(2004): Environment and Employment - An Assessment. OECD, Paris.

O'Mahony, M., and M. P. Timmer (2009): "Output, Input and Productivity Measures at the Industry Level: The EU KLEMS Database," The Economic Journal, 119, 374-409.

Palmer, K., W. OAtes, and P. Portney (1995): "Tightening environmental standards: the benefit-cost paradigm or the no-cost paradigm," Journal of Economic Perspectives.

Pasinetti, L. (1981): Structural Change and Economic Growth: A Theoretical Essay on the Dynamics of the Wealth of Nations. Cambridge University Press, Cambridge.

Pearce, D. (1991): "The Role of Carbon Tax in Adjusting to Global Warming," The Economic Journal, 101(407), 938-948.

Pigou, A. C. (1920): The Economics of Welfare. Macmillan, London.

Porter, M. E. (1990): The Competitive Advantage of Nations. MacMillan, London.

Proops, J. L., M. Faber, and G. Wagenhals (1993): Reducing $\mathrm{CO}_{2}$ Emissions - A Comparative Input-Output Study for Germany and the UK. Springer Verlag, Berlin, Heidelberg, New York.

Shackleton, R., M. Shelby, A. Cristofaro, R. Brinner, J. Yanchar, L. Goulder, D. Jorgenson, P. Wilcoxen, P. P. Shackleton, M. Shelby, and A. Cristofaro (1992): "The Efficiency Value of Carbon Tax Revenues," Discussion paper, U.S. Environmental Protection Agency.

Shah, A., And B. Larsen (1992): "Carbon Taxes, the Greenhouse Effect and Developing Countries," Discussion paper, The World Bank, Washington, D.C.

Stern, N. (2007): The Economics of Climate Change: The Stern Review. Cambridge University Press, Cambridge.

Uzawa, H. (2003): Economic Theory and Global Warming. Cambridge University Press, Cambridge.

VAN DER Linde, C. (1993): "The micro-economic implications of environmental regulation: a preliminary framework," Discussion paper, OECD, Paris.

Weitzmann, M. (2008): "On Modeling and Interpreting the Economics of Catastrophic Climate Change," Working Paper. 